\title{
Role of stromal cell-derived factor 1 (SDF1/CXCL12) in regulating anterior pituitary function
}

\author{
Federica Barbieri, Adriana Bajetto, Carola Porcile, Alessandra Pattarozzi, Gennaro Schettini \\ and Tullio Florio \\ Section of Pharmacology, Department of Oncology Biology and Genetics, University of Genova, Viale Benedetto XV, 2, 16132 Genova, Italy
}

(Requests for offprints should be addressed to T Florio; Email: tullio.florio @ unige.it)

\begin{abstract}
Chemokines are key factors involved in the regulation of immune response, through the activation and control of leukocyte traffic, lymphopoiesis and immune surveillance. However, a large number of chemokines and their receptors are expressed in central nervous system (CNS) cells, either constitutively or induced by inflammatory stimuli, playing a role in many neuropathological processes. Stromal cell-derived factor 1 (SDF1) is a chemokine whose extra-immunological localization and functions have been extensively studied. SDF1 and its receptor CXCR4 were identified in both neurons and glia of many brain areas, including the hypothalamus, as well as at the pituitary level. Importantly, SDF1 and CXCR4 expression is increased in brain tumors in which their activity induced tumor cell proliferation and brain parenchyma invasion. Despite their localization, to date very few reports addressed the role of CXCR4 and SDF1 in the modulation of the hypothalamus/pituitary axis and their possible involvement in the development of pituitary adenomas. In this review, we discuss previous literature data on the role of chemokines in normal and adenomatous pituitary cells, focusing on recent data from our group showing that CXCR4 activation controls proliferation and both prolactin and $\mathrm{GH}$ release in the pituitary adenoma cell line $\mathrm{GH} 4 \mathrm{C} 1$ through a complex network of intracellular signals. Thus, the SDF1/CXCR4 system together with other chemokinergic ligand-receptor pairs, may represent a novel regulatory pathway for pituitary function and, possibly, be involved in pituitary adenoma development. These lines of evidence suggest that the inhibition of chemokine receptors may represent a novel pharmacological target for the treatment of pituitary adenomas.
\end{abstract}

Journal of Molecular Endocrinology (2007) 38, 383-389

\section{Role of chemokines in neuroendocrine regulation}

Stromal cell-derived factor 1 (SDF1), also called CXCL12, is a chemokine of the CXC subfamily originally characterized as a pre-B-cell stimulatory factor and cloned from bone marrow cell supernatants. SDF1 exists in three alternative splicing variants $(\alpha, \beta$ and $\gamma)$, of which SDF1 $\alpha$ is the most abundant in the brain (Nagasawa et al. 1994). The sequence of this chemokine is highly conserved among the species, with only one amino acid difference between murine and human SDF1 $\alpha$, suggesting that this molecule may play a significant biological role. SDF1 is a chemotactic factor for $\mathrm{T}$ cell, monocytes, pre-B-cells, dendritic cells, and hematopoietic progenitor cells and supports B-cell progenitor and CD34 ${ }^{+}$cell proliferation (Luster 1998, Christopherson \& Hromas 2001). However, its expression is not restricted to immune and hematic cells, but SDF1 mRNA and protein were also identified in the central nervous system (CNS) in neuronal, astroglial, microglial, and endothelial cells (Bajetto et al. 2001a).
SDF1 exerts its effects via the binding to CXCR4, a receptor member of the G-protein-coupled receptor superfamily. Their interaction is reported to be unique, different from other chemokines that recognize multiple receptors. The disruption of CXCR4 or SDF1 genes in mice, causes a similar embryological lethal phenotype, characterized by deficient B-lympho- and myelo-poiesis, defects in vasculogenesis and abnormal development of the heart and of different areas of the CNS (Nagasawa et al. 1996, Zou et al. 1998). Similarly to SDF1, CXCR4 is expressed outside the immune system, including endothelial cells, embryonic germinal neuroepithelium and mature neurons, astrocytes and microglia (Oh et al. 2001). Furthermore, CXCR4 was reported to represent a co-receptor of CD4 for the entry of T-lymphotropic strains of the immunodeficiency virus (HIV-1); SDF1, competing for CXCR4, can inhibit the fusion and replication of HIV1 in $\mathrm{CD}^{+} / \mathrm{CXCR}^{+}$cells (Feng et al. 1996).

Interestingly, besides a specific distribution of both SDF1 and CXCR4 in different brain areas and neuronal subpopulations, a selective localization of SDF1 
expressing neurons was detected in many hypothalamic nuclei, including the paraventricular nucleus (PVN), the lateral hypothalamus, the lateral pre-optic area and the median eminence (Banisadr et al. 2003, Guyon et al. 2005). Furthermore SDF1 was reported to inhibit arginine vasopressin (AVP) release from the magnocellular neurons of the supraoptic and the paraventricular hypothalamic nuclei in normal rat. In addition, AVP projections to the anterior pituitary co-express SDF1 and CXCR4 thus demonstrating that the SDF1/CXCR4 axis represents an autocrine system that modulates brain and neuroendocrine activity (Callewaere et al. 2006). Importantly, although the majority of the SDF1labeled neurons belonged to the magnocellular subpopulation projecting to the neurohypophysis, SDF1 expressing neurons, even though less numerous $(20 \%$ of the neurons when compared with $60 \%$ in the vasopressinergic neurons), were also observed in the parvocellular part of the PVN (Banisadr et al. 2003).

\section{Chemokine modulation of normal pituitary function}

It has been known for many years that different immunederived molecules can control pituitary hormone release. In particular, it was reported that interleukin $1 \beta$ (IL-1 $\beta$ ), that is produced by hypothalamic neurons (Johnson et al. 2004) inhibit prolactin secretion from dispersed rat pituitary cells through the regulation of both cAMP production and agonist-induced $\mathrm{Ca}^{++}$fluxes (Schettini et al. 1990). Indeed, the expression of its receptors was detected within the mouse adenohypophysis (Cunningham et al. 1992). Moreover, IL-1 $\beta$ mRNA was identified in rat pituicytes after a lipopolysaccharide (LPS) challenge, supporting the hypothesis that IL-1 $\beta$ may be involved in paracrine or autocrine regulation of pituitary function during infectious challenge (Koenig et al. 1990). However, the role of IL-1 $\beta$ in the brainendocrine-immune axis is not yet completely defined. Similarly also interleukin 6 (IL-6) is released by normal rat pituitary cells (Spangelo et al. 1990a) and its receptor was also identified in normal pituicytes in humans (Hanisch et al. 2000). The pituitary source of IL-6 was identified in the folliculostellate (FS) cells in normal tissue and a paracrine mechanism was proposed for the cytokine regulation of different pituitary hormones release, including adrenocorticotropic hormone (ACTH) and prolactin (Woloski et al. 1985, Spangelo et al. 1989).

However, to date none of these studies supported a physiological role for these cytokines in pituitary function. Indeed, it was proposed that their functional effects are mainly dependent on endotoxin challenge and thus a response to infections (Spangelo et al. 1990b).

In the past years, a better defined regulation of the hypothalamic-hypophyseal axis by some pleiotropic chemokines was identified in rat. In fact, the cytokineinduced neutrophil chemoattractant (CINC, the rat counterpart of the human growth-related oncogene, GRO) was reported to be expressed in the PVN, the posterior pituitary and the median eminence. In response to stressful stimuli (i.e. immobilization stress) CINC synthesis is highly induced in the PVN and the chemokine is released in the median eminence (Sakamoto et al. 1996) to reach CXCR2 (the GRO receptor)-expressing pituitary cells. The biological effects of CINC on pituitary cells were the stimulation of prolactin release (and slight stimulation of GH secretion) and the inhibition of luteinizing hormone (LH) and follicle stimulating hormone (FSH) secretion (Sawada et al. 1994). Importantly, CXCR2 expression was identified also in normal human pituitary cells, thus supporting the relevance of this regulatory mechanism (Tecimer et al. 2000). Furthermore, a sustained CINC secretion was also observed in a subpopulation of cultured pituitary cells (Koike et al. 1994) and by FS cells (Zhang et al. 1997). Thus, again an autocrine/paracrine intrapituitary regulation may occur via the CINC/GRO stimulation of pituitary cells expressing CXCR2. However, GRO is not the only chemokine that may be involved in the regulation of pituitary function. For example, another CXCR2 ligand, interleukin 8 (IL-8), was also identified in brain areas (PVN of the hypothalamus and hippocampus) involved in the hypothalamus-pituitary-adrenal axis. Importantly, its secretion is under the control of steroids through a feedback mechanism, thus supporting a physiological role for this chemokine in the pituitary regulation of ACTH secretion (Licinio et al. 1992).

However, the chemokinergic regulation of the hypothalamus-pituitary system is still poorly studied, and we can hypothesize that more chemokine/receptor pairs are effectively involved in its regulation both in physiology and in pathology. For example, SDF1 is emerging as a major point of convergence between immune and nervous systems. In particular, binding studies showed that at the pituitary level, high affinity SDF1-binding sites were present (Banisadr et al. 2000), and CXCR4 mRNA was identified in rat anterior pituitary explants (Bajetto et al. 1999). Thus, the concomitant expression of SDF1 in hypothalamic neurons and CXCR4 at the pituitary level, may suggest that this chemokine could represent a novel hypothalamic factor possibly contributing to the regulation of anterior pituitary function.

\section{Pituitary and hypothalamic chemokines in the development of pituitary adenomas}

Pituitary adenomas constitute up to $15 \%$ of primary intracranial tumors and are associated with significant morbidity due to local mass-related effects and/or hormone hypersecretion. Pituitary adenomas are 
classified according to their secretory pattern: prolactinomas represent about 30\% of pituitary tumors, GH hypersecretive adenomas (GHoma) account for approximately $15 \%$, and ACTH-secreting tumors $<10 \%$. Pituitary adenomas secreting biologically inactive hormones ( $\alpha$ subunit of glycoproteic hormones, such as thyroid stimulating hormone (TSH), LH and FSH, or the entire gonadotropins) or derived from 'null cells' are defined as clinically 'non-functioning pituitary adenomas' (NFPAs) and represent about $30 \%$ of the total pituitary tumors. To date, most aspects of molecular pathogenesis of pituitary adenomas remain unclear since few alterations have been definitively demonstrated to be involved in their tumorigenesis (Asa \& Ezzat 2002).

Genetic studies reported that pituitary adenomas have a monoclonal origin with the neoplastic initiation often related to oncogenic mutations in proteins involved in cell proliferation control. Among others, mutations were identified in the genes encoding ras, PKC, the $\alpha$ subunit of the GTP-binding proteins Gs, $(g s p)$ or Gi (gip). Furthermore, in some cases the overexpression of activating genes (i.e. pituitary tumor transforming gene, $h p t t g$ ) or loss of tumor suppressor genes (Rb, menin, $p 53, p 27$ and $p 16)$ was identified (Spada \& Lania 2002).

Nevertheless, the pathogenesis of these tumors is heterogeneous with these genetic alterations identified only in subsets of adenomas. The current hypothesis proposes that these initiating events may cause a 'gain of function' in the proliferative activity of single pituitary cells on which promoting factors cooperate to induce the clonal expansion (Asa \& Ezzat 2002).

A multiplicity of promoting factors, such as hypothalamic hormones, locally produced growth factors (EGF, bFGF, FGF-4, NGF, TGF) and cytokines (IL-1, IL-2, IL-6), have been reported to determine pituitary tumor progression (Ray \& Melmed 1997, Renner et al. 2004).

Chemokines are now recognized as mediators in several physiologic and pathologic processes, including the proliferation and invasiveness of cancer cells. However, very few studies addressed the potential role of any component of the chemokine family in regulating pituitary functions. In particular, the receptor for IL-8, CXCR2, was detected in high concentration in human pituitary adenomas (Tecimer et al. 2000), suggesting a possible participation of this chemokine in the expansion of some pituitary adenomas. Interestingly, although there is an extremely variable incidence rate among different studies, that is, 3 out of 25 according to Suliman et al. (1999) or 17 out of 17 according to Green et al. (1996), the expression of IL-8 was also identified in adenoma pituitary cells altogether with its receptor; it is thus possible to hypothesize an autocrine/paracrine pathway of activation of the tumor cells.

On the other hand, SDF1 receptor CXCR4 is the most widely expressed chemokine receptor in human malignancies and its activation by SDF1 causes proliferation, migration, invasion, and metastatization of cancer cells and promotes tumoral neo-angiogenesis (Burger \& Kipps 2006). In particular, the SDF1/CXCR4 system was reported to support the survival and growth of leukemia, breast carcinoma (Balkwill 2004), and glioblastoma multiforme (GBM) cells (Rempel et al. 2000, Bajetto et al. 2006a). In vitro studies showed that SDF1 is a growth factor for GBM cells increasing their proliferation and migration (Barbero et al. 2003). In addition, it has been reported that SDF1 stimulates chemotaxis, survival and proliferation in GBM and medulloblastoma primary cell cultures and xenografted tumors (Rubin et al. 2003).

To date, the role of SDF1/CXCR4 in the pituitary function and in the genesis of pituitary adenomas has scarcely been investigated. However, the constitutive expression of the ligand and its cognate receptor in hypothalamic neurons and pituitary cells respectively, together with the powerful role demonstrated for SDF1 as tumor proliferation factor, suggest the possibility that this chemokine, via the activation of pituitary CXCR4, may act as a promoting factor for pituitary adenoma development.

\section{Biological effects of SDF1 in pituitary adenoma cells: the GH4C1 cell model}

We used the rat pituitary adenoma cell line GH4C1 to analyze the potential role of the SDF1/CXCR4 network in the regulation of pituitary function and, possibly, pituitary tumorigenensis (Florio et al. 2006). These cells represent one of the most studied model to evaluate pituitary regulation in vitro (Westendorf \& Schonbrunn 1982). GH4C1 cells display a regulated release of both $\mathrm{GH}$ and prolactin, and a proliferative response reproducing at best in vitro that observed in pituitary adenoma cells.

Importantly, we showed that, different from most of the tumor cell lines analyzed, these cells express CXCR4 but not SDF1. This feature is particularly important, since CXCR4 is known to go through a very rapid desensitization and thus, in the presence of an endogenous release of the chemokine in a closed system (as occurs in most in vitro studies), it could be very difficult to identify the effects of the exogenous peptide.

To assess a role for SDF1 in pituitary adenoma development, we tested, in this cell model, the effects of the chemokine in the regulation of the two key features of pituitary adenoma cells, hormone release, and proliferation.

We found that low nanomolar concentrations of SDF1 caused a significant increase in both prolactin and $\mathrm{GH}$ secretion, although the latter was much more pronounced $(+35$ and $+110 \%$ respectively when 
compared with the basal secretion of the two hormones; Table 1). This secretagogue activity was completely abolished by pretreatment with pertussis toxin or somatostatin (100 nM; Table 1). These data indicate that SDF1 activity requires the activation of a G-protein of the Gi/Go subfamily, and that its effects are responsive to inhibitory stimuli as observed in both normal pituitary and secreting adenomas. Interestingly, pertussis toxin was able to abolish both the stimulatory effects of SDF1 (Florio et al. 2006) and the inhibitory effects of somatostatin (Florio \& Schettini 1996).

SDF1 was also a powerful mitogen for GH4C1 cells, with a statistically significant effect already evident at a concentration of $6.25 \mathrm{nM}$ and reaching a maximal increase of DNA synthesis at a concentration of $12.5 \mathrm{nM}$ (Table 1). Higher concentrations either did not further increase the cell proliferation rate or even induced a lower effect, likely due to the rapid desensitization of CXCR4 caused by high ligand concentrations, as well characterized in other cell systems (Barbero et al. 2003). Importantly, the proliferative effects were also completely abolished by pertussis toxin and significantly reduced by somatostatin pretreatment (Table 1). The observation that pertussis toxin reversed both the stimulatory effects of SDF1 and the inhibitory action of somatostatin, depends on the observation that CXCR4 and all the somatostatin receptors are coupled to a pertussis toxinsensitive G-protein. However, the opposite biological effects observed can be understood by the different intracellular signaling activated by the respective receptors (for review see Florio \& Schettini 1996 and Bajetto et al. 2001a). For example, an opposite regulation of ERK1/2 activity was reported for CXCR4 (activation; Bajetto et al. 2001b) and the somatostatin receptors (inhibition; Massa et al. 2004).

To evaluate the relevance of these effects for pituitary functioning, we compared them with those induced by the known physiological pituitary regulator GHRH. Interestingly, we observed that the maximal proliferation induced by GHRH, was of the same magnitude as that obtained by SDF1 (Table 1).

Table 1 Effect of SDF1 on both GH secretion and proliferation of GH4C1 cells: comparison with GHRH-induced effects and antagonism by pertussis toxin or somatostatin pretreatment

$\begin{array}{llll} & \begin{array}{l}\text { GH } \\ \text { secretion } \\ \text { (\% of basal) }\end{array} & \begin{array}{l}\text { DNA } \\ \text { synthesis } \\ \text { (\% of basal) }\end{array} \\ & & \\ \text { SDF1 (12.5 nM) } & +110 & +98 \\ \text { SDF1 + pertussis toxin } & +6 & +12 \\ \text { SDF1+ somatostatin (100 nM) } & +13 & +38 \\ \text { GHRH (300 nM) } & +126 & +85\end{array}$

Data are expressed as percentage of respective basal values and are derived from Florio et al. (2006), except the somatostatin data that are unpublished observations from $\mathrm{F}$ Diana and T Florio.
Very recently, we reported some preliminary results showing the expression of SDF1 and CXCR4 in human pituitary adenoma postsurgical specimens (Bajetto $\mathrm{et} \mathrm{al}$. 2006b). When confirmed these data will surely contribute to the establishment of a role for this chemokine in pituitary tumor functioning.

\section{Intracellular mechanisms involved in SDF1 regulation of GH4C1 pituitary adenoma cell proliferation and $\mathrm{GH}$ release}

We used GH4C1 cells to evaluate the intracellular mechanisms activated by SDF1 to induce hormone release and cell proliferation (Florio et al. 2006). We analyzed a set of intracellular mediators that were previously involved in CXCR4 effects, namely the regulation of the intracellular $\mathrm{Ca}^{++}$concentration, the activation of ERK1/2 and of the cytosolic $\mathrm{Ca}^{++}$ dependent tyrosine kinase, $\mathrm{Pyk} 2$, and the stimulation of the large conductance, $\mathrm{Ca}^{++}$-activated $\mathrm{K}^{+}$channels $\mathrm{BK}_{\mathrm{Ca}}$. Interestingly, all these systems were activated following SDF1 treatment of GH4C1 cells.

Thus, using selective inhibitors on these intracellular pathways, we tried to establish a molecular ordering between the SDF1-activated second messengers. We used the cell permeable $\mathrm{Ca}^{++}$chelator BAPTA-AM to abolish the intracellular $\mathrm{Ca}^{++}$rise induced by the chemokine, the MEK inhibitor PD98059 to revert the activation of ERK1/2, salicylate to counteract Pyk2 activation, and TEA to prevent $\mathrm{BK}_{\mathrm{Ca}}$ channel activation. We found that the SDF1-dependent regulation of intracellular $\mathrm{Ca}^{++}$was independent of the activation of ERK1/2, Pyk2 or $\mathrm{BK}_{\mathrm{Ca}}$ (i.e. it was not inhibited by PD98059, salicylate or TEA) and that ERK1/2 activation lay on an independent pathway (it was not affected by BAPTA-AM, salicylate or TEA). Conversely, Pyk2 activation was $\mathrm{Ca}^{++}$dependent (it was blocked by BAPTA$\mathrm{AM}$, but not by PD98059 or TEA) and $\mathrm{BK}_{\mathrm{Ca}}$ channel activity was dependent on both the SDF1-induced intracellular $\mathrm{Ca}^{++}$rise (it was inhibited by BAPTA$\mathrm{AM})$ and Pyk2 activation (inhibition by salicylate).

Thus, in GH4C1 cells two independent pathways activated by SDF1 were identified: the first one is $\mathrm{Ca}^{++}$. independent and causes the activation of ERK1/2, likely through the $\beta \gamma$ subunit of $\mathrm{Gi}$, as reported for many G-protein-coupled receptors, and the second one is $\mathrm{Ca}^{++}$-dependent involving the sequential activation of Pyk2 and $\mathrm{BK}_{\mathrm{Ca}}$.

Using the same pharmacological approach, we tried to establish which of these pathways was involved in the control of GH release and which controls the cell proliferation induced by SDF1.

Interestingly, we found that the SDF1-induced GH release was a solely $\mathrm{Ca}^{++}$-dependent process, since it 


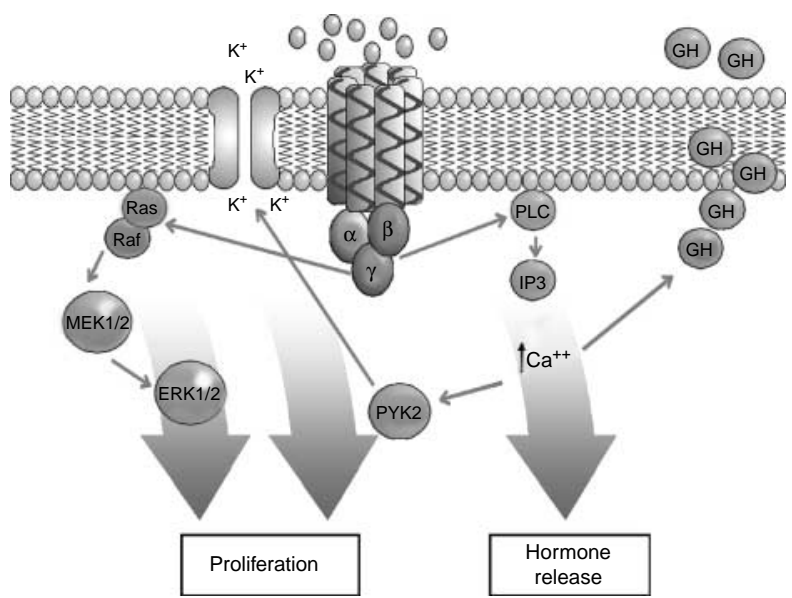

Figure 1 Schematic representation of the signal transduction pathways activated by SDF1 in the $\mathrm{GH} 4 \mathrm{C} 1$ pituitary adenoma cell line. SDF1 treatment is a powerful regulator of both cell proliferation and hormone release (Florio et al. 2006). SDF1induced proliferation signaling occurs through two signaling pathways; the first one is $\mathrm{Ca}^{++}$-independent and involves the ERK1/2 MAP kinase cascade, likely through the interaction of the $\beta \gamma$ complex with the GTPase Ras that mediates the sequential phosphorylation of the kinases Raf, MEK $1 / 2$ and ERK $1 / 2$. The second one is $\mathrm{Ca}^{++}$-dependent: the chemokine-induced $\mathrm{Ca}^{++}$ increase activates Pyk2, which, in turn, regulates the $\mathrm{BK}_{\mathrm{Ca}}$ channel activation. Conversely, $\mathrm{GH}$ secretion is a purely $\mathrm{Ca}^{+{ }^{+}}$dependent process: chemokine receptor causes the activation of PLC, which leads to IP3 formation and $\mathrm{Ca}^{++}$release from internal stores. Abbreviations: $\alpha-\beta-\gamma$ subunits of G-proteins; MEK1/2, MAP kinase kinase; ERK1/2, extracellular signal-regulated kinase 1 and 2; PYK2, cytosolic $\mathrm{Ca}^{++}$-dependent tyrosine kinase 2; PLC, phospholipase C; IP3, inositol 1,4,5-trisphosphate; $\mathrm{BK}_{\mathrm{Ca}}$, large conductance $\mathrm{Ca}^{++}$-activated $\mathrm{K}^{+}$channels.

was not abolished by the inhibitors of ERK1/2, Pyk2 or $\mathrm{BK}_{\mathrm{Ca}}$, but only by the $\mathrm{Ca}^{++}$chelator BAPTA-AM.

On the other hand, the regulation of GH4C1 cells proliferation induced by this chemokine was dependent on both the $\mathrm{Ca}^{++}$-independent stimulation of ERK1/2 activity and the $\mathrm{Ca}^{++}$-dependent activation of Pyk2 and $\mathrm{BK}_{\mathrm{Ca}}$. Importantly, each of the inhibitory compounds tested completely reverted the proliferative stimuli of SDF1, indicating that all these intracellular second messengers $\left(\mathrm{Ca}^{++}, \mathrm{Pyk} 2, \mathrm{BK}_{\mathrm{Ca}}\right.$ and ERK1/2) are necessary for such an effect. The schematic representation of intracellular pathways activated by SDF1 in GH4C1 cells is depicted in Fig. 1.

\section{Conclusions}

In this review, we analyze the potential role of chemokines and, in particular, of SDF1 as a novel pituitary growth factor. Although the role of growth factors in pituitary adenoma development and of chemokines (and SDF1, in particular) in the control the proliferation of many different tumor histotypes is well recognized, a possible chemokine regulation of pituitary function has never been addressed in a systematic way. We suggest that SDF1, coming from the systemic circulation or possibly released from hypothalamic neurons, may reach CXCR4 expressing cells to regulate pituitary function (Fig. 2).

Although previous work reported the localization of chemokine receptors (CXCR2 and 4) at the pituitary level their ligands (IL-8/GRO and SDF1) in hypothalamic neurons, their possible role in pituitary adenoma development was never studied. Recently, we showed that SDF1 is a powerful mitogen and

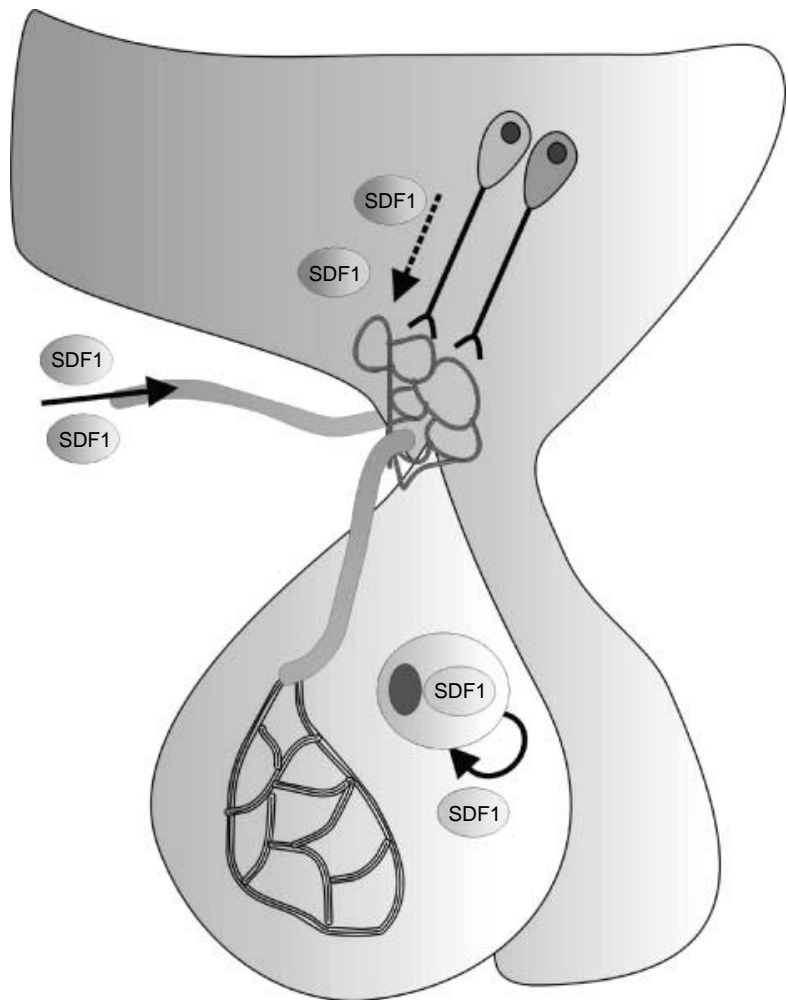

Figure 2 Possible mechanisms by which SDF1 can control the pituitary function and, possibly, stimulate pituitary adenoma cell proliferation. SDF1 can control pituitary cells function acting at different levels: (1) SDF1, released by hypothalamic neurons, may act as a novel hypophysiotrophic factor. This regulation may occur either by influencing the neuronal cells to produce hypothalamic releasing hormones, that control the anterior pituitary cells functions, or by being released by hypothalamic neurons and reaching via the pituitary portal system CXCR4-expressing pituitary cells (since most of the SDF1 releasing neurons project to the posterior hypophysis, dotted arrow indicates a less likely occurrence of such pathway of stimulation); (2) SDF1, coming from the systemic circulation can reach the pituitary, enters into the capillary net of the anterior lobe of the pituitary gland and interacts with pituitary cells that express CXCR4; (3) moreover, during pituitary adenoma development, SDF1 could be produced by anterior pituitary cells and, through an autocrine/paracrine process may stimulate adenohypophyseal tumor-initiated cells to proliferate and to hypersecrete specific hormones. This pathway may represent a promoting factor for pituitary adenoma development. 
secretagogue for the pituitary adenoma cell line GH4C1, and characterized the intracellular mechanisms involved in these effects. In particular, we demonstrated that a complex interplay of a multiplicity of second messengers was responsible for such regulation of pituitary adenoma cells. This observation may imply that the adenoma development could somehow be favored by the activation of an autocrine/paracrine stimulation of cell proliferation and hormone secretion induced by the adenomatous cells expressing the chemokine/receptor pair (Fig. 2). Importantly, similar data were also observed for the other chemokine IL-8, suggesting that the chemokinergic system may represent a novel pleiotropic regulator of pituitary function. Although the expression of SDF1 and CXCR4 was also identified in normal rat pituitary, the relevance of this chemokine in normal tissue represents an issue that needs to be addressed in the near future, especially as far as the evaluation of the level of expression in normal versus tumor tissue and whether normal and/or tumor pituitary cells co-express both the chemokine and its receptor, as observed for IL-8. Notwithstanding, these data are opening a very important new research area in the field of pituitary regulation that may lead to the identification of important new pharmacological targets (i.e. antagonists of CXCR4, such as the compound AMD3100 or newer derivatives Yan et al. 2006) for the therapy of pituitary adenomas.

\section{Acknowledgements}

This work was supported by an Italian Association for Cancer Research grant to TF. The authors declare that there is no conflict of interest that would prejudice the impartiality of this scientific work.

\section{References}

Asa SL \& Ezzat S 2002 The pathogenesis of pituitary tumours. Nature Reviews Cancer 2 836-849.

Bajetto A, Bonavia R, Barbero S, Piccioli P, Costa A, Florio T \& Schettini G 1999 Glial and neuronal cells express functional chemokine receptor CXCR4 and its natural ligand stromal cellderived factor 1. Journal of Neurochemistry 73 2348-2357.

Bajetto A, Bonavia R, Barbero S, Florio T \& Schettini G $2001 a$ Chemokines and their receptors in the central nervous system. Frontiers in Neuroendocrinology 22 147-184.

Bajetto A, Barbero S, Bonavia R, Pirani P, Piccioli P, Costa A, Florio T \& Schettini G $2001 b$ Stromal cell-derived factor-lalpha induces astrocyte proliferation through the activation of extracellular signalregulated kinases 1/2 pathway. Journal of Neurochemistry 77 $1226-1236$.

Bajetto A, Barbieri F, Dorcaratto A, Barbero S, Daga A, Porcile C, Ravetti JL, Zona G, Spaziante R, Corte G et al. 2006a Expression of CXC chemokine receptors $1-5$ and their ligands in human glioma tissues: role of CXCR4 and SDF1 in glioma cell proliferation and migration. Neurochemistry International 49 423-432.
Bajetto A, Porcile C, Pattarozzi A, Zona G, Spaziante R, Robello M, Ferone D, Minuto F \& Florio T $2006 b$ Role of the chemokine SDF1 in regulating anterior pituitary function. Abstract S43, Sixth International Congress of Neuroendocrinology, Pittsburgh (PA) USA.

Balkwill F 2004 Cancer and the chemokine network. Nature Reviews Cancer 4 540-550.

Banisadr G, Dicou E, Berbar T, Rostene W, Lombet A \& Haour F 2000 Characterization and visualization of $\left[{ }^{125} \mathrm{I}\right]$ stromal cellderived factor-lalpha binding to CXCR4 receptors in rat brain and human neuroblastoma cells. Journal of Neuroimmunology 110 151-160.

Banisadr G, Skrzydelski D, Kitabgi P, Rostene W \& Parsadaniantz SM 2003 Highly regionalized distribution of stromal cell-derived factor1/CXCL12 in adult rat brain: constitutive expression in cholinergic, dopaminergic and vasopressinergic neurons. European Journal of Neuroscience 18 1593-1606.

Barbero S, Bonavia R, Bajetto A, Porcile C, Pirani P, Ravetti JL, Zona GL, Spaziante R, Florio T \& Schettini G 2003 Stromal cell-derived factor lalpha stimulates human glioblastoma cell growth through the activation of both extracellular signal-regulated kinases $1 / 2$ and Akt. Cancer Research 63 1969-1974.

Burger JA \& Kipps TJ 2006 CXCR4: a key receptor in the crosstalk between tumor cells and their microenvironment. Blood 107 1761-1767.

Callewaere C, Banisadr G, Desarmenien MG, Mechighel P, Kitabgi P, Rostene WH \& Melik Parsadaniantz S 2006 The chemokine SDF-1/ CXCL12 modulates the firing pattern of vasopressin neurons and counteracts induced vasopressin release through CXCR4. PNAS 103 $8221-8226$.

Christopherson K II \& Hromas R 2001 Chemokine regulation of normal and pathologic immune responses. Stem Cells 19 388-396.

Cunningham ET Jr, Wada E, Carter DB, Tracey DE, Battey JF \& De Souza EB 1992 In situ histochemical localization of type I interleukin-1 receptor messenger RNA in the central nervous system, pituitary, and adrenal gland of the mouse. Journal of Neuroscience 12 1101-1114.

Feng Y, Broder CC, Kennedy PE \& Berger EA 1996 HIV-1 entry cofactor: functional cDNA cloning of a seven-transmembrane, G protein-coupled receptor. Science 272 872-877.

Florio T \& Schettini G 1996 Multiple intracellular effectors modulate physiological functions of the cloned somatostatin receptors. Journal of Molecular Endocrinology 17 89-100.

Florio T, Casagrande S, Diana F, Bajetto A, Porcile C, Zona G, Thellung S, Arena S, Pattarozzi A, Corsaro A et al. 2006 Chemokine stromal cell-derived factor lalpha induces proliferation and growth hormone release in $\mathrm{GH} 4 \mathrm{Cl}$ rat pituitary adenoma cell line through multiple intracellular signals. Molecular Pharmacology 69 539-546.

Green VL, Atkin SL, Speirs V, Jeffreys RV, Landolt AM, Mathew B, Hipkin L \& White MC 1996 Cytokine expression in human anterior pituitary adenomas. Clinical Endocrinology 45 179-185.

Guyon A, Rovere C, Cervantes A, Allaeys I \& Nahon JL 2005 Stromal cell-derived factor-1alpha directly modulates voltage-dependent currents of the action potential in mammalian neuronal cells. Journal of Neurochemistry 93 963-973.

Hanisch A, Dieterich KD, Dietzmann K, Ludecke K, Buchfelder M, Fahlbusch R \& Lehnert H 2000 Expression of members of the interleukin-6 family of cytokines and their receptors in human pituitary and pituitary adenomas. Journal of Clinical Endocrinology and Metabolism 85 4411-4414.

Johnson JD, O'Connor KA, Watkins LR \& Maier SF 2004 The role of IL-1beta in stress-induced sensitization of proinflammatory cytokine and corticosterone responses. Neuroscience 127 569-577.

Koenig JI, Snow K, Clark BD, Toni R, Cannon JG, Shaw AR, Dinarello CA, Reichlin S, Lee SL \& Lechan RM 1990 Intrinsic pituitary interleukin-1 beta is induced by bacterial lipopolysaccharide. Endocrinology 126 3053-3058. 
Koike K, Sakamoto Y, Sawada T, Ohmichi M, Kanda Y, Nohara A, Hirota K, Kiyama H \& Miyake A 1994 The production of CINC/gro, a member of the interleukin- 8 family, in rat anterior pituitary gland. Biochemical and Biophysical Research Communications 202 161-167.

Licinio J, Wong ML \& Gold PW 1992 Neutrophil-activating peptide-1/ interleukin-8 mRNA is localized in rat hypothalamus and hippocampus. Neuroreport 3 753-756.

Luster AD 1998 Chemokines-chemotactic cytokines that mediate inflammation. New England Journal of Medicine 338 436-445.

Massa A, Barbieri F, Aiello C, Arena S, Pattarozzi A, Pirani P, Corsaro A, Iuliano R, Fusco A, Zona G et al. 2004 The expression of the phosphotyrosine phosphatase DEP-1/PTPeta dictates the responsivity of glioma cells to somatostatin inhibition of cell proliferation. Journal of Biological Chemistry 279 29004-29012.

Nagasawa T, Kikutani H \& Kishimoto T 1994 Molecular cloning and structure of a pre-B-cell growth-stimulating factor. PNAS 91 2305-2309.

Nagasawa T, Hirota S, Tachibana K, Takakura N, Nishikawa S, Kitamura Y, Yoshida N, Kikutani H \& Kishimoto T 1996 Defects of B-cell lymphopoiesis and bone-marrow myelopoiesis in mice lacking the CXC chemokine PBSF/SDF-1. Nature 382 635-638.

Oh JW, Drabik K, Kutsch O, Choi C, Tousson A \& Benveniste EN 2001 CXC chemokine receptor 4 expression and function in human astroglioma cells. Journal of Immunology 166 2695-2704.

Ray D \& Melmed S 1997 Pituitary cytokine and growth factor expression and action. Endocrine Reviews 18 206-228.

Rempel SA, Dudas S, Ge S \& Gutierrez JA 2000 Identification and localization of the cytokine SDF1 and its receptor, CXC chemokine receptor 4 , to regions of necrosis and angiogenesis in human glioblastoma. Clinical Cancer Research 6 102-111.

Renner U, Paez-Pereda M, Arzt E \& Stalla GK 2004 Growth factors and cytokines: function and molecular regulation in pituitary adenomas. Frontiers of Hormone Research 32 96-109.

Rubin JB, Kung AL, Klein RS, Chan JA, Sun Y, Schmidt K, Kieran MW, Luster AD \& Segal RA 2003 A small-molecule antagonist of CXCR4 inhibits intracranial growth of primary brain tumors. PNAS 100 13513-13518.

Sakamoto Y, Koike K, Kiyama H, Konishi K, Watanabe K, Tsurufuji S, Bicknell RJ, Hirota K \& Miyake A 1996 A stress-sensitive chemokinergic neuronal pathway in the hypothalamo-pituitary system. Neuroscience 75 133-142.

Sawada T, Koike K, Sakamoto Y, Nohara A, Kanda Y, Zhang ZX, Ohmichi M, Yamaguchi M, Hirota K \& Miyake A 1994 In vitro effects of CINC/GRO, a member of the interleukin-8 family, on interleukin- 6 secretion by rat posterior pituitary cells. Biochemical and Biophysical Research Communications 200 742-748.
Schettini G, Florio T, Meucci O, Landolfi E, Grimaldi M, Lombardi G, Scala G \& Leong D 1990 Interleukin-1-beta modulation of prolactin secretion from rat anterior pituitary cells: involvement of adenylate cyclase activity and calcium mobilization. Endocrinology 126 $1435-1441$

Spada A \& Lania A 2002 Growth factors and human pituitary adenomas. Molecular and Cellular Endocrinology 197 63-68.

Spangelo BL, Judd AM, Isakson PC \& MacLeod RM 1989 Interleukin-6 stimulates anterior pituitary hormone release in vitro. Endocrinology $125575-577$.

Spangelo BL, Isakson PC \& MacLeod RM 1990a Production of interleukin- 6 by anterior pituitary cells is stimulated by increased intracellular adenosine $3^{\prime}, 5^{\prime}$-monophosphate and vasoactive intestinal peptide. Endocrinology 127 403-409.

Spangelo BL, Judd AM, MacLeod RM, Goodman DW \& Isakson PC $1990 b$ Endotoxin-induced release of interleukin- 6 from rat medial basal hypothalami. Endocrinology 127 1779-1785.

Suliman ME, Royds JA, Baxter L, Timperley WR, Cullen DR \& Jones TH 1999 IL-8 mRNA expression by in situ hybridisation in human pituitary adenomas. European Journal of Endocrinology 140 155-158.

Tecimer T, Dlott J, Chuntharapai A, Martin AW \& Peiper SC 2000 Expression of the chemokine receptor CXCR2 in normal and neoplastic neuroendocrine cells. Archives of Pathology and Laboratory Medicine 124 520-525.

Westendorf JM \& Schonbrunn A 1982 Bombesin stimulates prolactin and growth hormone release by pituitary cells in culture. Endocrinology 110 352-358.

Woloski BM, Smith EM, Meyer WJ III, Fuller GM \& Blalock JE 1985 Corticotropin-releasing activity of monokines. Science $\mathbf{2 3 0}$ $1035-1037$.

Yan L, Anderson GM, DeWitte M \& Nakada MT 2006 Therapeutic potential of cytokine and chemokine antagonists in cancer therapy. European Journal of Cancer 42 793-802.

Zhang ZX, Koike K, Sakamoto Y, Jikihara H, Kanda Y, Inoue K, Hirota K \& Miyake A 1997 Pituitary folliculo-stellate-like cell line produces a cytokine-induced neutrophil chemoattractant. Neuropeptides $\mathbf{3 1}$ $46-51$.

Zou YR, Kottmann AH, Kuroda M, Taniuchi I \& Littman DR 1998 Function of the chemokine receptor CXCR4 in haematopoiesis and in cerebellar development. Nature 393 595-599.

Received in final form 8 November 2006

Accepted 4 December 2006

Made available online as an Accepted Preprint 28 December 2006 